\title{
BIM IN THE PRE-CONSTRUCTION PHASE: AN INFRASTRUCTURE PROJECT CASE STUDY
}

\author{
Aline V. Arrotéia ${ }^{1}$ and Silvio B. Melhado ${ }^{2}$
}

\begin{abstract}
BIM adoption represents an uphill task for the construction industry in developing nations. In Brazil, construction companies are looking out for the best strategies to implement BIM into their processes. Currently, the industry relies on traditional methods which fall short of meeting the demand for the interconnection between different levels of information along the building life cycle, especially in highly complex projects. The research goal was to understand the main obstacles with BIM adoption during the pre-construction phase in a complex infrastructure project. The research methodology was exploratory and qualitative carried out through a single case study approach made upon bibliographical research, project analysis, interviews, and informal conversations. Based on that, our analysis discussed the results from two different perspectives: BIM in the company's organizational context and BIM in the pre-construction phase. After that, we summarize the main barriers and gaps concerning BIM in the case study. Results has shown the main difficulties faced by the company in their efforts to thoroughly implement BIM. Mainly, the project studied has achieved 3D dimension modeling and a punctual initiative of 4D dimension application during the pre-construction and construction phases. In conclusion, this study has observed the importance of the pre-construction phase for the successful information management and project results in terms of constructability, cost saving and time management.
\end{abstract}

Keywords: BIM, BIM adoption, 3D modeling, 4D scheduling, pre-construction phase, construction industry.

\section{INTRODUCTION}

Many decisions during construction are postponed due to the parallelism of design and construction activities faced by highly complex projects such as infrastructure and industrial projects (Francis and Miresco, 2016). BIM has become a common process and technology used in the management of construction projects (Puolitaival and Forsythe, 2016). As an alternative for highly complex projects, construction companies focused on infrastructure and industrial projects are considering BIM implementation in order to minimize problems related to design and construction interface.

However, the construction industry in developing countries such as Brazil is still facing challenges on BIM implementation. The main obstacles are related to the need on the change of work culture and practices, the lack of understanding of the stakeholders 'roles and responsibilities, the lack of knowledge about processes and workflows and the highly investment in training and skills required for BIM (Olawumi, 2018; Mahalingam et al. 2015; Khosrowshahi and Arayici 2012; Singh et al. 2011; Hartmann and Fischer, 2008).

Considered as an innovative process and efficient technology, BIM manages project information from the design to construction and operation in a collaborative way (Donato

PhD researcher, University of Sao Paulo, Sao Paulo, Brazil, aline.arroteia@usp.br

Associate professor, University of Sao Paulo, Sao Paulo, Brazil, silvio.melhado@usp.br 
et al., 2018). Although in the past decade, there have been significant advances in construction-related collaborative technologies, BIM implementation is a long path and depends on many aspects, such as the adequate methodology, trained personnel, the availability of technology and industry policies (Akintola et al., 2017).

Given the field of study's relevance to the development of construction sector in Brazil, the research goal was to understand the main obstacles with BIM adoption during the preconstruction phase in a complex infrastructure project. This study shows a preliminary result of an ongoing data collection from a case study of a doctorate research.

Our paper is structured as follows: First, we introduce the research topic and propose the research goal. Second, we contextualize literature review by discussing BIM in developing countries, BIM in Brazil, and BIM in the pre-construction phase. Third, we outline methodology characterized by research steps and data collection. Forth, we present case study description by detailing information regarding the company and the project selected. After, we show the results from two different perspectives: BIM in the company's organizational context, BIM in the pre-construction phase, and then we present the main obstacles concerning BIM adoption in the project selected. Finally, we conclude by presenting research goal achievement, research limitations, future works suggestion and recommendations.

\section{LITERATURE REVIEW}

\subsection{BIM in developing countries}

BIM adoption in the construction industry is growing as technology matures (Turk, 2016). BIM promises an integration of information by combining geometric and non-geometric information in a comprehensive model that accommodate all aspects of construction (Koutamanis (2017). A study developed by Cao et al. (2015), has shown an overview of BIM practice through a decade in China and confirmed that BIM adoption has been clearly extended from the architectural design stage to the construction stage.

Even though BIM has been continually expanding its functionality in the construction industry since its inception in the 1970s, BIM has not been fully exploited even in leading contexts. Mostly, there is a higher level of awareness of BIM in the UK, Canada, Finland and New Zealand then compared to developing countries ( $\mathrm{Gu}$ and London, 2010; Ghaffarianhoseini et al., 2017).

BIM is not just a technology, but also a project management tool and process consisted of all aspects, disciplines, and systems of a facility within a model, with which all stakeholders (owners, architects, engineers, contractors, subcontractors and suppliers) can collaborate more accurately and efficiently than traditional processes (Succar, 2009; Succar, 2015; Azhar et al, 2012).

Despite the rapid development of BIM, the effectiveness in the practice is constrained by the current contractual arrangements and traditional practices. There is a reluctance to change traditional practices and current procedures by the professionals in order to learn BIM. In general, projects are more focused on individual benefits instead of the delivery of integrated project solutions (Love et al, 2014; Migilinskas, 2013).

In Brazil and other developing countries, BIM requires a significant change in the way construction businesses operate at almost every level within a building process (Arayici et al., 2011). As stated by Succar et. al. (2013), BIM is a continuous and long process which need to be improved step by step passing through all BIM stages and requires new strands of expertise for all disciplines compared to more traditional projects. 


\subsection{BIM in Brazil}

In 2017, the Brazilian Government created a strategic committee dedicated to BIM adoption namely CE-BIM to diffuse the usage of BIM in the construction sector though modernization and the digital transformation. Based on a Federal Decree, the Brazilian Government has established the BIM BR Strategy as a national plan of BIM dissemination, systematized by purposes, objectives (indicators and milestones) and actions. Nine main objectives were defined to achieve the expected results (Brasil, 2018):

1. Spread BIM concepts and its benefits

2. Coordinate the structuring of public sector for BIM adoption

3. Create conditions for public and private investments in BIM

4. Encourage BIM training

5. Propose normative and parameters for BIM-based procurement and public bidding

6. Develop technical standards, guides, and specific protocols for BIM adoption

7. Develop a platform and BIM national library

8. Encourage the development and the application of new technologies related to BIM

9. Encourage market competition through neutral standards of BIM interoperability.

The CE-BIM has proposed a BIM BR roadmap to be developed in 10 years, from 2018 to 2028 in three main phases. All three phases involve the development of architectural and engineering projects for new constructions, extensions, and retrofits:

- Phase 1 (From January 2021): BIM adoption in the design phase. Application of BIM models for clash detections among disciplines such as structuring, electrical, pipeline, HVAC (heating, ventilation, and air condition), quantitative take-offs and graphic documentation.

- $\quad$ Phase 2 (From January 2024): BIM adoption in the design and construction phases. Project planning, management and procurement of the construction phase and the design as-built model.

- $\quad$ Phase 3 (From January 2028): BIM adoption in the whole building life cycle phases (design, construction, and operation/maintenance). This phase also considers the development of BIM models for facility management.

Therefore, there are many initiatives being developed in Brazil to promote BIM adoption in the construction sector. In addition to the Brazilian Government initiative, the Brazilian Association of Technical Standards -ABNT has defined a set of six technical standards related to BIM including modeling object requirements, guidelines for libraries, system classification and information management in construction.

Furthermore, the Brazilian Chamber of the Construction Industry-CBIC has elaborated a guide named by BIM Implementation Collection for Builders and Developers aiming to (Cbic, 2016):

- Develop a clear understanding of BIM applications by orienting its application for construction companies and developers

- Clarify, influence, and facilitate a common technological platform between all construction stakeholders.

Allied to the Brazilian government, associations and syndicates from the construction sector have been doing many efforts towards to BIM adoption in the construction sector. Likewise, academia and research labs are developing studies attempting to better incorporate BIM into Brazilian context. 


\subsection{BIM in the pre-construction phase}

BIM is new to many companies and its adoption is consequently challenging. Challenges include unstructured processes that often leads to time and cost overruns (Grytting et al., 2017). Despite the advances in construction management methods and systems over the previous decades, project managers still facing a variety of problems related to the management of partial and heterogeneous data and the manipulation of information (Francis, 2013).

During the pre-construction phase, 3D and 4D modeling techniques can be used to simulate the construction process through a BIM model and detect operation succession errors and space use conflicts (Francis, 2019). As more information becomes available over time and the level of risk decreases, it becomes much easier to make better-informed decisions according to the status of the project or based on the available budget (Francis and Miresco, 2016). Current scheduling methods do not account for spatiotemporal constraints, which leads to less than optimal scheduling. This failure causes problems which thus affects the project's duration and cost (Francis, Miresco and Le Meur, 2019).

\section{Methodology}

As mentioned before, our main purpose was to investigate a case of BIM adoption in the pre-construction a large construction company in the Brazilian context. The methodology was exploratory and qualitative, through a single case study. According to Yin (2015), single case studies aim to understand the research topic through a broad description and a deep analysis in a company or organization (Yin, 2015). As sources of evidence we adopted bibliography, project analysis, interviews, and informal conversations. The units of analysis were project, company and people, and the geographical scope of the study was national.

\subsection{Research Steps}

The research was developed in four main steps. First, we concentrated on studying of the topic's theoretical background and on selecting the company. Second, after the company and project selection, we focused on the project analysis such as project's contract, project scope and schedule and the design deliverables. Third, we interviewed key stakeholders involved in BIM implementation in the company and in the pre-construction phase of the chosen project. Lastly, we focused on data analysis by discussing results obtained from the company's and project documents, interviews, and informal conversations.

\subsection{Data Collection}

Data collection was retrospective and developed from September to December of 2019 and gathered using a semi structured research protocol. The research protocol contains two different semi structured questionnaires which were applied according to the stakeholders' position in the company and project. The first questionnaire aimed to collect data regarding BIM adoption in the company's organizational context. This questionnaire was applied to the stakeholders, who had participated actively in the implementation process.

The second questionnaire focused on the understanding of the main barriers and gaps related to BIM adoption in the pre-construction phase. We interviewed stakeholders involved in the design and construction phases of the project selected. These stakeholders may not had participated in the BIM implementation process in the company. 
Most of the data were obtained from the interviews with key project's stakeholders. According to Blumberg et al. (2011) interviews provide rich data collection by allowing an expansion and clarification of questions and answers during the interview process. In this case, the interview process was oriented by the research protocol using the semi structured questionnaires, with clarifications being made by using complementary questions throughout the interviews when necessary. Annotations were made and the interviews were recorded and transcribed for content data analysis. Participants were informed that the responses were completely anonymous and confidential, and each one signed a consent form. Interviews were applied with four key stakeholders as illustrated in Table 1.

Table 1. Interviewed project's stakeholders

\begin{tabular}{|c|c|c|c|c|c|}
\hline N. & $\begin{array}{l}\text { Stakeholder's position in } \\
\text { the company/project }\end{array}$ & $\begin{array}{l}\text { Years of } \\
\text { experience } \\
\text { in the } \\
\text { position }\end{array}$ & $\begin{array}{l}\text { Years } \\
\text { working } \\
\text { in the } \\
\text { company }\end{array}$ & $\begin{array}{l}\text { Educational } \\
\text { background }\end{array}$ & Questionnaire type \\
\hline 1 & $\begin{array}{l}\text { Head of BIM applications/ } \\
\text { Bidding }\end{array}$ & 3 years & 10 years & $\begin{array}{l}\text { Civil } \\
\text { Engineering }\end{array}$ & $\begin{array}{l}\text { Questionnaire 1: BIM } \\
\text { implementation in } \\
\text { the company }\end{array}$ \\
\hline 2 & BIM specialist & 2 years & 2 years & $\begin{array}{l}\text { Production } \\
\text { Engineering }\end{array}$ & $\begin{array}{l}\text { organizational } \\
\text { context }\end{array}$ \\
\hline 3 & Business Developer & 5 years & 8 years & $\begin{array}{l}\text { Electrical } \\
\text { Engineering }\end{array}$ & \multirow{2}{*}{$\begin{array}{l}\text { Questionnaire } 2 \text { : BIM } \\
\text { adoption in the pre- } \\
\text { construction phase }\end{array}$} \\
\hline 4 & Project Engineering Manager & 5 years & 13 years & $\begin{array}{l}\text { Chemical } \\
\text { Engineering }\end{array}$ & \\
\hline
\end{tabular}

\section{CASE STUDY}

\subsection{Company}

The company selected for this study is a relevant and well-known multinational Brazilian construction company with over 70 years of experience in the infrastructure sector. Since 1948, the company has developed more than 900 projects, such as industrial, infrastructure, energy, oil, gas, and urban mobility all over Brazil and in more than 40 countries as well. The company's technical capacity goes beyond the execution of construction projects, including the design of projects, purchases, manufacturing and assembly, project management and contracts.

The company's organizational structure is mainly formed by nine corporative units/departments named: finances, planning and risk business, juridical, engineering, management center, supply chain, people management, excellence and innovation, and equipment. With more than 10 thousand employers (office and construction team), the company has five offices located in Brazil and other six abroad. There are two main headquarters, one placed in the city of Rio de Janeiro and another one in São Paulo, Brazil.

The company holds several national and international awards and certifications, such as ISO 9001, ISO 14001, ISO 19600, OHSAS 18001, AS 8000, SGQ: Sistema de Gestão da Qualidade, SGI: Sistema de Gestão Integrado and PBQP-H: Programa Brasileiro da Qualidade e Produtividade do Habitat (in Portuguese) ${ }^{3}$. In 2018, due to market demand

\footnotetext{
${ }^{3}$ Quality Management System, SGI: Integrated Management System, and PBQP-H: Brazilian Habitat
} Quality and Productivity Program. 
and considering the company's previous experience with BIM, the head of the company established BIM implementation as a fundamental part of the company's strategic planning for the following three years (from 2018 to 2020). Therefore, BIM implementation is an ongoing process in the company. The project selected for this study is a pilot project of an initial BIM adoption as detailed below.

\subsection{Project}

The project is a Brazilian consortium of an Engineering, Procurement and Construction (EPC) contract tasked to execute a thermoelectric power plant for liquified natural gas (LNG) storage. The project is being developed by two main contractors and one engineering subcontractor, a Spanish outsourced engineering company, which is responsible for the design. The company selected for this study is one of the contractors in charge of the management of design and construction teams and the execution of the thermoelectric power plant.

In November of 2017, the project contract was signed and the first mobilizations for construction started in March of 2018. The expected deadline for starting to deliver energy is in the beginning of 2021. At the time of data collection, the project stage was at electromechanical assembly and testing the plant's commissioning. The project's scope consists of the design, the procurement and the providing of all equipment, installations, construction, commissioning, and start-up. The development of the thermoelectric power plant involved six main disciplines: civil, metallic, mechanic, pipeline, electric and instrumentation.

The project is being built in a 15,700-ha area located in the city of São João da Barra, north of Rio de Janeiro's state in Brazil. The thermoelectric power plant is a combined cycle gas turbine (CCGT) with $1238 \mathrm{MW}$ net installed capacity and a configuration of $3 \times 3 \times 1$ ( 3 gas turbines, 3 HRSGs and 1 steam turbine). The gas turbines will have single fuel capability with natural gas and the steam exhausting from the steam turbine will be condensed through a seawater cooling tower system. Figure 1 illustrates the project chosen for this study.
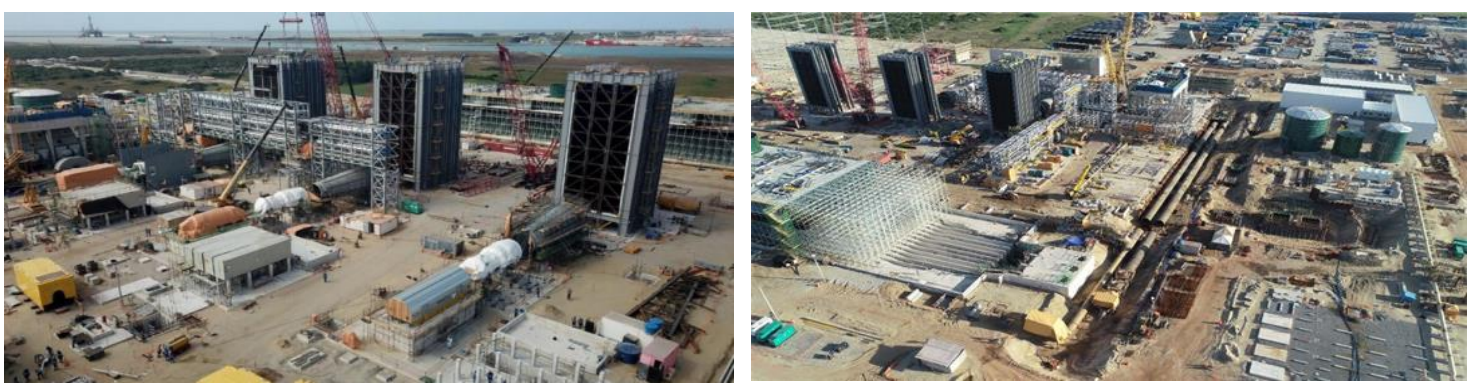

Figure 1: Project's upper view picture (Source: company's documents) 


\section{RESULTS DISCUSSION}

Results are discussed and presented in consonance with the research protocol's structure as cited in the methodology section.

\subsection{BIM in the company's organizational context}

In 2008, the company started the first initiatives related to 3D modeling in industrial projects. Ten years later, in 2018 due to the market demand, BIM adoption was incorporated as a part of the company's strategic plan with the purpose to delivery more value to clients through a digital model and to develop a more integrated process able to manage project information and stakeholders in all project phases.

A team of eight professionals has been created to implement BIM. This team was divided in two different BIM adoption approach. The first team focused on the development of BIM interfaces and the second one on the expansion of BIM applications subdivided into BIM proposal applications and BIM construction applications. As a result, BIM process was delineated to be implemented in three main phases:

- Phase 1: Structuring (2018): embodiment of BIM in the company's organizational level. This phase worked on the understanding how BIM could be insert into the actual company project workflow. At the same time, the team focused on the studying of BIM as a concept, management tool, software, and process.

- Phase 2: Training (2019): investments on professional training, consulting, and BIM related courses. This phase aimed to spread BIM adoption into other departments.

- Phase 3: Implementing (2020): BIM adoption thorough pilot projects and achieving BIM maturity level gradually by doing trial and error during the design and construction process and by giving feedbacks. At the moment of data collection, the company is concentrated on the activities of phases 2 and 3.

Results have shown the main difficulties experimented by the participants during BIM implementation were lack of trained professionals, lack of digital materials and standards, work culture resistance to the adoption of new technologies, highly investment on training, hardware, and software. Additionally, BIM has brought a changing on policies and process practiced by the company.

Since BIM implementation has started in the company, standards and guides are being renewed and incorporated into the design process based on BIM concepts. Also, contracts have been developed in a different way based on the level of development (LOD) by discipline and adapted accordingly to the design typology.

According to the participant's opinion, BIM implementation has impacted more in process when compared to technology and people category. For them, BIM was considered more efficiently in the design phase and flawed in the construction phase. Operation phase was not considered once the company does not work with facility management contracts. Participants responded that they have been receiving positive feedbacks from their clients concerning design quality after BIM adoption. Finally, in a scale from 1 to 5 , which one is initial and five is optimized, BIM maturity level was classified between level 2-3.

\subsection{BIM in the pre-construction phase}

During the interview process, our investigation has started firstly questioning if the company adopt any kind of method or solution during the pre-construction phase of the project that helps to mitigate the lack of communication and integration between design- 
construction phases. After that, we continue by interrogating about BIM adoption during the pre-construction phase itself.

Due to the project's complexity, since the beginning of the pre-construction phase, a multidisciplinary team has been working on mitigating the lack of information between design-construction phases. A team of professionals was composed by approximately 1525 people from different design disciplines. The number of professionals varies according to the construction work's demands.

Since 2014, the company adopted a web-based platform named by plannerly as a technological tool of design-construction interface. This platform manages all project activities and information by doing a project planning, scoping, scheduling, tracking and viewing during pre-construction and construction phases.

Concerning BIM model applications, the project studied achieved mainly 3D dimension (modeling) and a few punctual initiatives of 4D dimension application (construction scheduling and sequencing) during the pre-construction and construction phases. By considering that BIM still being an ongoing process in the company this scenario could be expected. On the other hand, the participants pointed a list of benefits that BIM adoption has brought to the pre-construction phase such as:

- better understanding of the design scope

- more collaboration among stakeholders

- more interaction with clients

- exchange of information and knowledge management

- design validation (clash detection) among disciplines

- cost estimation and quantity take off.

Finally, participants affirmed that BIM has improved design and construction interface by integrating players from different areas such as engineering, construction, planning and supply chain. Likewise, BIM has brough improvements on site layout, planning and safety, a reduction of claims and risks during the pre-construction and construction phases. As consequence, based on the participant's answers, we believe that BIM has enhanced design and construction interface decreasing project fragmentation by offering a better communication among the design and construction players and a better management of the project information.

\subsection{Main obstacles concerning BIM}

During the interview process we observed a misunderstanding regarding the interaction and communication between the stakeholders. Some of them affirmed that BIM promoted an increasing of interaction between design and construction team. Other ones responded that the physical distance among players was a significant barrier, due to the design team was placed in Spain, the engineering team in São Paulo and the construction site in city of São João da Barra, Rio de Janeiro’s state, Brazil.

From our findings we noticed the importance to incorporate BIM in the contract before the beginning of the project. By specifying the level of development (LOD) of each design discipline in the BIM model and how the deliverables would bring more constructability to the construction process in order to help diminishing problems related to the design and construction interface. Besides the improvements cited before, results have shown the main obstacles and gaps faced by the company during BIM adoption were: 
- Difficulty to achieve the necessary level of development of the 3D model able to develop 4D construction scheduling and sequencing (3D+time)

- Difficulty to encourage the players to work together "in the same page"

- Lack of communication among stakeholders

- Lack of collaboration between all design disciplines

- Lack of knowledge of the design team concerning construction's needs

- Lack of knowledge of the outsourced design's company concerning the BIM

- Lack of interoperability between software and high cost and investment in software and hardware.

\section{CONCLUSIONS}

Based on our research goal, we understood the main obstacles with BIM adoption during the pre-construction phase are related to managerial problems than with BIM itself. Therefore, we acknowledge the need of collaborative work environment with design and construction players. We understood the importance to approximate design players with construction job site putting them to work together with the construction team in order to mitigate the problems related to the project fragmentation by improving project's constructability, performance, and quality. Furthermore, we recognized the necessity of the construction players started to work in the very beginning of the design phase by bringing their experience of constructability to the design team.

Concerning BIM in the company's organizational context, we know BIM implementation is an ongoing process in the company which has started almost two years ago. Due to the short period of time of BIM adoption we did not expected a different result. As stated by Succar (2009), any company can start from Pre-BIM status and go up direct to Full BIM status. BIM is a continuous and long process which need to be improved step by step passing through all BIM stages. Regarding the BIM level of maturity in the company, we made a comparison between the results and theory. Participants classified the company's level of maturity between 2-3 level which represents in theory from defined (level 2) to managed (level 3) as stated by Succar (2015).

In relation to BIM in the pre-construction phase, we observed a significant concern from the company' viewpoint on providing an accurate information to the construction team from a multidisciplinary design team working on the development of design's feasibility. Therefore, we comprehend the pre-construction phase is a paramount importance for the successful information management and, anyhow, the design professionals and construction players should actively participate on this phase in order to improve project results in terms of constructability, cost saving and time management.

The emergent need for collaborative work involving the design professionals and construction players was stressed along the interviews. This need seems to be even more demanded during the technological transition to BIM processes. The case studied is an example on how construction contracts should change in order to foster collaboration across stakeholders as well as between design and site managers, thereby achieving a higher level of improvement potentially carried on by the new technologies.

The construction industry is a complex and fragmented environment. In developing countries such as Brazil the reality is not different. There is a lack of policies, standards and guides which should be developed from the government sphere in order to brings more quality to the construction industry due to the relevance of this sector for the economic 
development in the country. The lack of qualified people in the construction site and the lack of knowledge concerning project and process management are another constraint.

Finally, besides the complexity of the project studied and the company's relevance in the construction industry in Brazil, this research has some limitations of methodological approach. First, as a single case study, the findings cannot be generalized. Second, this study was dependent on the participants' self-reported perceptions. Third, new studies should be conducted with others construction companies aiming a comparison between them from a perspective of another project and a different company's organizational structure. An interesting area for future research could be an investigation of BIM adoption in others project's typologies or in the public sector.

\section{FUNDING}

This study was financed in part by the Coordenação de Aperfeiçoamento de Pessoal de Nível Superior - Brasil (CAPES) - Finance Code 001".

\section{ACKNOWLEDGMENTS}

The authors thank the company selected for giving us all the necessary support and data for the development of this research. Even more we acknowledge all the participants, who took the time to answer interview questions; without them this study would not be possible.

\section{REFERENCES}

Akintola, A., Venkatachalam, S., Root, D. (2017), "New BIM Roles' Legitimacy and Changing Power Dynamics on BIM-Enabled Projects", Journal of Construction Engineering and Management, DOI: 10.1061/(ASCE)CO.1943-7862.0001366.

Arayici, Y., Coates, P., Koskela, L., Kagioglou, M., Usher, C., O’Reily, K. (2011). "Technology adoption in BIM implementation for lean architectural practice", Automation in Construction, Vol. 20, pp. 189-195.

Azhar, S., Khalfan, M., Maqsood, T. (2012). Building Information Modeling (BIM): now and beyond, Construction Economics and Building 12 (4), 15-28.

BRASIL, Federal homepage (2018). Estratégia BIM BR: Estratégia Nacional de Disseminação do Building Information Modelling-BIM. Available at:

http://www.mdic.gov.br/images/REPOSITORIO/sdci/CGMO/Livreto Estratgia BIM BR -6.pdf [Accessed at 8 April 2020).

BRASIL, Federal homepage (2020). Decreto №10.306 of 2 de abril de 2020. Available at: http://www.planalto.gov.br/ccivil_03/_Ato2019-2022/2020/Decreto/D10306.htm [Accessed at 8 April 2020).

Blumberg, B., Cooper, D. R., Schindler, P. S. (2011). Business Research Methods. 3rd edition. McGraw-Hill Higher Education, Berkshire.

Cao, D., Wang, G., Li, H., Skitmore, M., Huang, T., Zhang, W. (2015) Practices and effectiveness of building information modelling in construction projects in China, Automation in Construction, Vol. 49, pp. 113-122.

CBIC (2016). Coletânea Implementação do BIM para construtoras e incorporadoras. Available at: https://cbic.org.br/faca-o-download-da-coletanea-bim-no-site-da-cbic/ [Accessed at 10 April 2020). 
Donato, V., Lo Turco, M., Bocconcino, M. M. (2017). "BIM-QA/QC in the architectural design process", Architectural Engineering and Design Management, 1-16, DOI:10.1080/17452007.2017.1370995.

Francis, A., Miresco, E., Le Meur, E. (2019). Spatiotemporal chronographical modeling of procurement and material flow for building projects. Advances in Computational Design, Vol. 4 (2), pp. 119-139 doi: https://doi.org/10.12989/acd.2019.4.2.119

Francis, A. (2019). Chronographical Spatiotemporal Scheduling Optimization for Building Projects. Frontiers in Built Environment, Vol. 5, pp. 114. https://doi.org/10.3389/fbuil.2019.00036

Francis, A., Miresco, E. (2016). Simulation of Execution Alternatives Using Chronographic Scheduling Logic. Journal of Civil Engineering and Science (JCES), Vol. 5 (1), pp. 1-8.

Francis, A. (2013). The Chronographical approach for construction project modelling. Management, Procurement and Law, Vol. 166 (4), pp. 188-204.

Ghaffarianhoseini, A., Tookey, J., Ghaffarianhoseini, A., Naismith, N., Azhar, S., Efimova, O., Raahemifar, K. (2017). "Building Information Modelling (BIM) uptake: Clear benefits, understanding its implementation, risks and challenges", Renewable and Sustainable Energy Reviews, Vol. 75, pp. 1046-1053.

Grytting, I., Svalestuen, F., Lohne, J., Sommerseth, H., Augdal, S., Lædre, O. (2017). Use of LoD decision plan in BIM-projects. In: I Creative Construction Conference 2017, Proceedings... Elsevier, Croatia: CCC, 2017. 8. Primosten, Croatia.

$\mathrm{Gu}, \mathrm{N}$. and London, K. (2010). "Understanding and facilitating BIM adoption in the AEC industry", Automation in Construction, Vol. 19, pp. 988-999.

Hartmann, T., and Fischer, M. (2008). "Applications of BIM and hurdles for widespread adoption of BIM.” In: 2007 AISC-ACCL eConstruction Roundtable Event Report, 2008.

Khosrowshahi, F., and Arayici, Y. (2012). "Roadmap for implementation of BIM in the U.K. construction industry." Journal of Engineering Construction and Architectural Management, 19(6), 610-635.

Koutamanis, A. (2017), "Briefing and Building Information Modelling: Potential for integration”, International Journal of Architectural Computing, Vol. 15(2), p.119-133.

Love, P.E.D., Matthews, J., Simpson, I.S., Hill, A. and Olatunji, O.A. (2014), "A benefits realization management building information modeling framework for asset owners", Automation in Construction, Vol. 37, pp. 1-10.

Mahalingam, A., Yadav, A. K., and Varaprasad, J. (2015). "Investigating the role of lean practices in enabling BIM adoption: Evidence from two Indian cases." Journal of Construction Engineering and Management, DOI: 10.1061/(ASCE)CO.19437862.0000982, 05015006.

Migilinskas, D., Popov, V., Juocevicius, V., Ustinovichius, L. (2013). The Benefits, Obstacles and Problems of Practical BIM Implementation. In: 11th International Conference on Modern Building Materials, Structures and Techniques, MBMST 2013, Vol. 57, pp. 767-774.

Olawumi, T. O., Chan, D. W. M., Wong, J. K. W., Chan, A. P. C. (2018). "Barriers to the integration of BIM and sustainability practices in construction projects: A Delphi survey of international experts." Journal of Building Engineering, Vol. 20, p. 60-71, DOI: $10.1016 /$ j.jobe.2018.06.017

Puolitaival, T., Forsythe, P. (2016) "Practical challenges of BIM education", Structural Survey, Vol. 34 (4/5), p.351-366, doi:10.1108/SS-12-2015-0053

Singh, V., Gu, N., and Wang, X. (2011). "A theoretical framework of a BIM-based multidisciplinary collaboration platform." Automation in Construction, Vol. 20 (2), p. 134144. 
Succar, B., Kassem, M. (2015). Macro-BIM adoption: conceptual structures. Automation in Construction, Vol. 57, p. 64-79.

Succar, B. (2009), "Building information modelling framework: A research and delivery foundation for industry stakeholders", Automation in Construction, Vol. 18, p.357-375.

Succar, B., Sher, W. and Williams, A. (2013), "An integrated approach to BIM competency assessment, acquisition and application", Automation in Construction, Vol. 35, p.174189.

Turk, Z. (2016). Ten questions concerning Building Information Modeling, Building and Environment, 107, pp. 274-284.

Yin, R. K. (2015). Case study research: design and methods. $6^{\circ}$ edition. Sage Publications. 